\title{
STUDIES OF CALCIUM AND PHOSPHORUS METABOLISM. XVI. THE INFLUENCE OF THE PITUITARY GLAND ${ }^{1}$
}

\author{
By WALTER BAUER AND JOSEPH C. AUB \\ (From the Medical Clinics of the Massachusetts General Hospital and the Collis P. Huntington \\ Memorial Hospital, and the Department of Medicine, Harvard \\ Medical School, Boston, Massachusetts)
}

(Received for publication December 9, 1940)

The literature pertaining to the effects of the anterior pituitary gland on calcium and phosphorus metabolism, well summarized by Zwarenstein (1) and Houssay (2), is meager and the results reported are contradictory. This is due in part to the fact that many of the previous workers employed inert anterior pituitary gland preparations.

In 1934 Hertz and Kranes (3) and Anselmino, Hoffmann and Herold (4) found that injections of an alkaline extract of the anterior pituitary gland into rabbits and rats caused hypertrophy of their parathyroid glands. Marenzi and Gerschman (5), working with dogs, were unable to demonstrate such an effect regularly.

Alterations in the blood calcium have rarely been observed following either hypophysectomy or the administration of anterior pituitary gland extracts. Hogben (6) did report the occurrence of a low blood calcium in the toad (Xenopus Laevi) following removal of the anterior pituitary and the pars intermedia. He further stated that injections of pituitary extracts caused a fall in the blood calcium. These observations have been confirmed by Shapiro and $Z$ warenstein (7).

The evidence suggesting that the pituitary influences the parathyroid glands and calcium and phosphorus metabolism in higher animals is even more conflicting. Gerschman and Marenzi (8), working in Houssay's laboratory, found no change in the blood calcium of hypophysectomized dogs but did observe an elevation following the administration of an alkaline anterior pituitary extract, a finding previously noted in one dog by Thompson and Cushing (9). Subsequently, Marenzi and Gerschman (10) reported that such extracts were without effect on the blood calcium of four thyroparathyroidectomized dogs. Because of the

\footnotetext{
1 The expenses of this investigation were aided in part by a grant from the Commonwealth Fund.
}

extreme difficulty in maintaining such experimental animals in a constant state, too much significance cannot be attached to these results. Friedgood (11) and Friedgood and McLean (12) noted increased blood calcium levels in rats and guinea pigs when alkaline anterior pituitary extracts were given. A tendency to a negative calcium balance in hypophysectomized rats, counteracted by injections of growth-promoting pituitary extracts, was observed by Pugsley and Anderson (13).

The literature may be summarized as follows: Injections of alkaline anterior pituitary extracts produce hypertrophy of the parathyroid glands and may cause elevation of the blood calcium level. It has not been definitely proved that this latter effect is lost in the absence of the thyroid and parathyroid glands. Hypophysectomy does not alter the blood calcium level of animals other than the toad.

The evidence favoring a relationship of the pituitary to the parathyroid glands and calcium and phosphorus metabolism in man consists of histological material collected by Cushing and Davidoff (14) and metabolism studies on two acromegalic patients $(15,16)$. Scriver and Bryan (15) studied a case of acromegaly with marked osteoporosis. Although they demonstrated the existence of a negative calcium balance, they presented no data supporting the view that hyperfunction of the thyroid and parathyroid glands played any rôle in the production of this metabolic alteration. The case studied by Langeron et al. (16) showed a reversal to a positive calcium balance following roentgen ray therapy to the pituitary gland. The metabolic regime which they employed was not described, the dietary regime was most haphazard, and only two one-day metabolic studies were made.

The purpose of this report is to present the calcium, phosphorus and nitrogen metabolism studies of five patients suffering from varying 
WALTER BAUER AND JOSEPH C. AUB

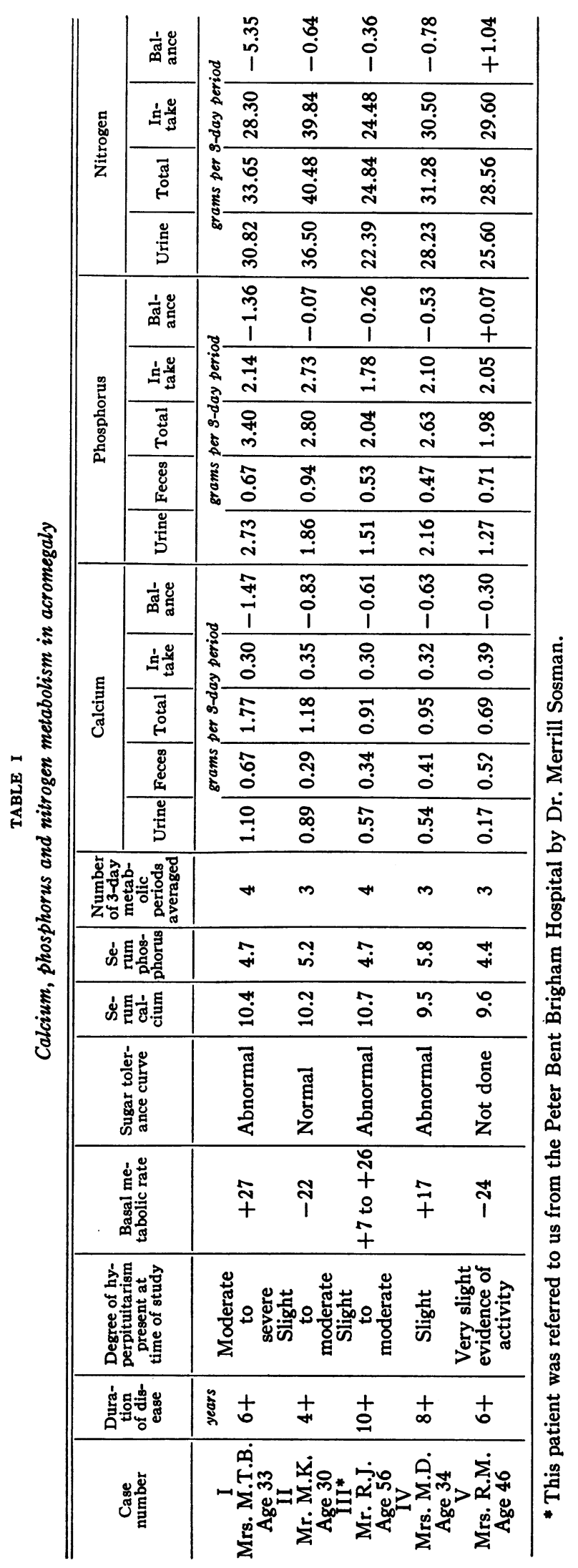


grades of uncomplicated acromegaly, to discuss the alterations observed and to comment upon the effects of roentgen ray therapy.

\section{METHODS}

The metabolic methods of ward management and analyses of blood and excreta were the same as we have employed previously (17). The patients were maintained on a constant low calcium, neutral diet similar to that used in later studies $(19,20)$, thus affording a satisfactory basis of comparison with our normal control subjects who were individuals between 19 and 60 years of age. The patients were all conscientious individuals, well suited for metabolic investigations.

\section{RESULTS}

Four patients with varying grades of acromegaly all showed a calcium excretion well above that found in normal individuals on the same dietary intake. Case V, who was believed to have only very slight evidence of increased activity of the pituitary, showed a normal excretion (Table I). The average calcium excretion per 3-day period, shown in Table II, is seen to be approximately twice that of the control subjects. It is further noted that the excess calcium appears in the urine. Expressed as milligrams of calcium excreted per kilogram body weight, the acromegalics excreted $19 \mathrm{mgm}$. per kgm., as compared to $12.7 \mathrm{mgm}$. per $\mathrm{kgm}$. for the normal individuals. The highest value, $27.4 \mathrm{mgm}$. per $\mathrm{kgm}$., was seen in Case I. As will be seen from Table I, the calcium excretion was higher in the patients who clinically had the more active disease.

TABLE II

Average calcium excretion per 3-day period on a low calcium neutral diet

\begin{tabular}{l|c|c|c|c}
\hline \hline & $\begin{array}{c}\text { Number } \\
\text { of } \\
\text { patients }\end{array}$ & Urine & Feces & Total \\
\cline { 2 - 4 } & & grams & grams & grams \\
Controls......... & 9 & 0.19 & 0.39 & 0.58 \\
Acromegalics..... & 5 & 0.65 & 0.45 & 1.10 \\
Excluding Case V. & 4 & 0.78 & 0.43 & 1.21 \\
\hline
\end{tabular}

Two of the acromegalics (Case I and Case III) were studied before and after roentgen ray therapy to the pituitary gland. Table III shows that in Case I both the calcium and phosphorus excre-
TABLE III

Average calcium and phosphorus excretion per 3-day period before and after roentgen ray therapy

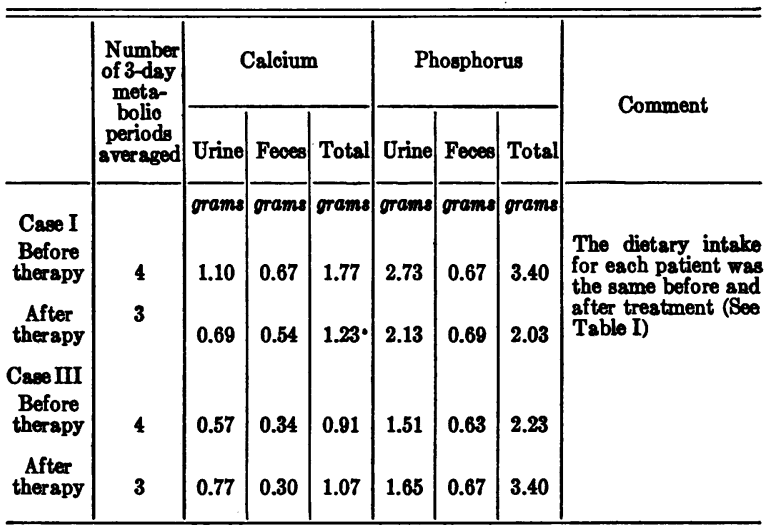

tions were reduced after such treatment. Clinical improvement was so great that the patient refused operative intervention. Case III, studied 40 days after the second course of roentgen ray therapy (a total of $2700 \mathrm{r}$ units was given each time to the pituitary body), received no apparent clinical benefit from these treatments, the basal metabolic rate was unchanged, and the calcium excretion remained essentially the same.

All patients except Case V showed negative phosphorus and nitrogen balances. The average phosphorus loss was somewhat greater than might be expected considering the $\mathrm{N} / \mathrm{P}$ and $\mathrm{Ca} / \mathrm{P}$ ratios.

At the suggestion of Dr. J. H. Means, Case III received Lugol's solution in order to determine if it would have any effect on the basal metabolic rate and the calcium and phosphorus excretions. The iodine solution was given 10 days prior to, as well as during, the period of observation. Table IV shows that it exerted no effect. This

\section{TABLE IV}

The basal metabolic rate and the average calcium and phosphorus excretion per 3-day period in Case III before and during the administration of Lugol's solution

\begin{tabular}{|c|c|c|c|c|c|c|c|c|}
\hline & \multirow{2}{*}{$\begin{array}{l}\text { Number } \\
\text { of 3-day } \\
\text { meta- } \\
\text { bolio } \\
\text { periods } \\
\text { averaged }\end{array}$} & \multicolumn{3}{|c|}{ Calcium } & \multicolumn{3}{|c|}{ Phosphorus } & \multirow{2}{*}{$\begin{array}{c}\text { Basal metabolio } \\
\text { rate }\end{array}$} \\
\hline & & Urine & Feces & Total & Urine & Feces & Total & \\
\hline & & grams & grams & grams & grams & grams & grams & \\
\hline Before & 4 & 0.57 & 0.34 & 0.91 & 1.51 & 0.53 & 2.04 & $+26,+11,+15,+7$ \\
\hline During & 3 & 0.54 & 0.43 & 0.97 & 1.60 & 0.63 & 2.23 & +1 to +13 \\
\hline
\end{tabular}

is contrary to Friedgood's experience with guinea pigs receiving injections of anterior pituitary ex- 
tract (18). He found that the basal metabolic rate was lowered when Lugol's solution was administered to these animals.

That the observed increased calcium excretion is not the result of an increased metabolic rate is well illustrated in Table I. Here an increased calcium excretion is seen in Case II, despite the fact that the basal metabolic rate was -22 . Likewise, an increased calcium excretion was observed in one case of Cushing's basophilism with a very low metabolic rate $(19,20)$. Furthermore, it has been shown that the elevated metabolism produced by leukemia and fever is not accompanied by an increased calcium excretion (21).

\section{DISCUSSION}

From the data presented it is apparent that the calcium and phosphorus metabolism of acromegalics differs from that of normal individuals. This abnormality is characterized by an increased urinary calcium and phosphorus output, the serum calcium and phosphorus and the fecal calcium and phosphorus being normal. This metabolic finding is not encountered in either hyperthyroidism or hyperparathyroidism. In the former, both the urinary and fecal calcium and phosphorus excretions are increased, and the blood values are normal. In hyperparathyroidism, the increased urinary calcium and phosphorus excretions are associated with a hypercalcemia and a hypophosphatemia. From our data it would seem unlikely that the observed increased urinary calcium excretion of the acromegalic is the result of stimulation of the thyroid and the parathyroid glands by the pituitary. However, it is impossible to rule out such a relationship. This same pituitary effect is observed in Cushing's basophilism syndrome (due to a basophilic adenoma), a disease characterized by a low metabolic rate $(20,22)$. From the present data it would appear wiser to assume that the anterior pituitary gland influences the calcium metabolism and that no relationship with other glands of internal secretion has been established. Thus it would appear that another endocrine gland is capable of influencing the rate of calcium exchange.

\section{CONCLUSIONS}

Patients with acromegaly have an abnormal calcium and phosphorus metabolism characterized by an increased urinary excretion of these minerals, although the blood and fecal calcium and phosphorus values are normal. These increased excretion rates roughly parallel the intensity of the disease but are not dependent upon an elevated basal metabolic rate.

Roentgen ray therapy of the pituitary gland caused a reduction in the urinary calcium and phosphorus excretion in one patient and was without effect in another. The administration of Lugol's solution to one patient did not alter the basal metabolic rate or the calcium and phosphorus metabolism.

It is therefore concluded that the pituitary gland must be considered one of the factors capable of altering the calcium and phosphorus metabolism.

\section{PROTOCOLS}

Case I, Mrs. M. T. B., a 33-year-old, married housewife, was admitted to the hospital on March 24, 1927, because of amenorrhea and acromegalic features. Her past history was essentially negative. She had been married 14 years and had 2 children living and well. There had been no other pregnancies and no miscarriages. Six years before her menses had ceased. About this same time she noticed that the features of her face were coarser, her lips thicker, and that she required a larger hat. Definite enlargement of the hands and feet was also observed. All these changes gradually increased up to the time of her entrance to the hospital. She further complained of loss of libido, weakness and frontoparietal headaches which occurred about once a month, lasted 24 to 48 hours, and were never accompanied by nausea and vomiting. There was no history of blurring or dimness of vision.

On physical examination the patient was found to be a large-framed woman showing coarse facial features, thick, moist skin, prominent superciliary ridges, a large, broad nose, large ears, marked prognathism, widely separated teeth and an enlarged tongue. The eyes were slightly more prominent than normal. The margins of the discs were blurred. Vision was normal. The visual fields were normal. The isthmus of the thyroid was enlarged. Examination of the heart, lungs and abdomen was negative. The blood pressure was 180/100. A slight right dorsal and left lumbar scoliosis was present. The uterus was slightly enlarged and retroverted. The hands and feet were larger and thicker than normal; the fingers and toes were broad. A neurological examination was negative.

Laboratory examinations were as follows: Routine blood and urine examinations were negative. Renal function tests were normal. Blood Wassermann was negative. The basal metabolism test was +27 per cent. Sugar tolerance test (100 grams of glucose) : 


\begin{tabular}{|c|c|}
\hline Time & $\begin{array}{l}\text { Blood sugar } \\
\text { mgm. per } 100 \mathrm{cc} .\end{array}$ \\
\hline 30 minutes & 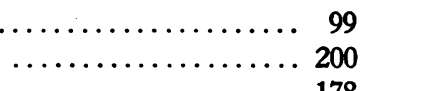 \\
\hline 60 minutes & $\ldots \ldots \ldots \ldots \ldots \ldots \ldots 178$ \\
\hline
\end{tabular}

Roentgenograms showed a thickened skull, a definitely enlarged sella turcica with some destruction of the floor and the posterior clinoid processes, enlarged sinuses, prominent mandible with separated teeth, spade-like hands and feet, with some tufting of the terminal phalanges.

Metabolic studies were made before the patient was given a course of deep $x$-ray therapy. The $x$-ray treatment resulted in disappearance of the headaches, increase in strength and a better state of wellbeing without any obvious change in the acromegalic features. She was re-admitted to the hospital on February 14, 1928, for further metabolic studies. She had been symptom-free since her first entrance. Physical examination at this time showed no new findings. The sugar tolerance curve was almost identical with that of the previous year, and the basal metabolism test was +25 per cent.

Impression: Acromegaly with moderate to severe hyperpituitarism probably due to an acidophilic adenoma of the anterior lobe of the pituitary.

Case II, Mr. M. K., a 30-year-old, unmarried, Jewish upholsterer, was referred to the hospital on April 4, 1927 , for study because of obvious acromegalic features. The patient had always been considered "a weak and sickly child." His past history was irrelevant except for typhoid fever at 21 years of age. It was difficult to determine the exact time of onset of his various symptoms. These were weakness, dizziness, headaches, easy fatigability, drowsiness, increased appetite and constipation. Enlargement of the hands and feet was first noticed 4 years previously. His weight of 174 pounds had remained unchanged during these 4 years.

Physical examination revealed a large-framed man with coarse features, coarse, moist skin, normal distribution of body hair, a widened nose, thick lips, an enlarged tongue, separated teeth and prognathism. The tonsils were enlarged. Examination of the heart, lungs and abdomen was negative. The blood pressure was $130 / 85$. His hands were enlarged and spade-like in appearance. His feet were enlarged and showed broad toes. Neurological examination was normal.

The laboratory examinations were as follows: Routine blood and urine examinations were normal. Blood Wassermann was negative. The basal metabolism test was -22 per cent. Sugar tolerance test (100 grams of glucose) :

\begin{tabular}{|c|c|}
\hline Time & $\begin{array}{l}\text { Blood sugar } \\
m g m \text { per } 100 \mathrm{cc} \text {. }\end{array}$ \\
\hline $\begin{array}{l}\text { Fasting ... } \\
30 \text { minutes }\end{array}$ & $\begin{array}{llr} & 91 \\
\ldots \ldots \ldots \ldots & 125\end{array}$ \\
\hline 60 minutes & c........... 140 \\
\hline 120 minutes & 127 \\
\hline 180 minutes & $\ldots \ldots \quad 115$ \\
\hline
\end{tabular}

Roentgenograms showed definite enlargement of the sella turcica with some erosion of the clinoid processes, enlarged sinuses, hypertrophy of the mandible, separation of the teeth, tufting of the terminal phalanges and broad metacarpals.

Impression: Acromegaly, probably due to a slow growing acidophilic adenoma of the anterior lobe of the pituitary or one which had ceased to grow. The patient had hyperpituitarism, but the basal metabolism test and sugar tolerance curve suggested that the activity of the pituitary was much less marked at the time he was studied than it had been.

Case III, Mr. A. R. J., a 56-year-old, married, unemployed insurance agent, first entered the hospital in May, 1936, because of acromegalic features. His past history was essentially negative except that he had suffered from mild Raynaud's disease for 20 years. He had been married 26 years and had 3 children. Ten years prior to entry, a friend first called attention to his acromegalic features. The patient thought they had become more marked since then, although he denied increase in size of head, hands and feet. Two years before, he first noted separation of the teeth, a dorsal kyphosis and forward bulging of the chest. His other complaints were weakness, loss of energy, easy fatigability, a voracious appetite, increased sweating and slight progressive blurring of vision.

On physical examination the patient was found to be a tall, well-developed, somewhat undernourished man. He had a well-defined dorsal kyphosis. His chest was barrel-shaped. He had a warm, moist, thick skin, moderately enlarged superciliary ridges, broadening of the nose, moderate prognathism, separation of the teeth and enlargement of the tongue. Examination of the eyes revealed haziness of the lens, marked myopia and upper bitemporal quadrantic anopsia. The thyroid was not enlarged. Examination of the heart and lungs was negative. The blood pressure was 120/90. The liver and spleen were felt one finger's breadth below the costal margin. The right kidney pole was palpable. The genitalia were normal. The hands and feet seemed slightly enlarged, the fingers and toes being broader than normal. Neurological examination was negative.

The laboratory examinations were as follows: Routine blood and urine examinations were normal. Fasting nonprotein nitrogen and blood sugar were normal. Blood Wassermann was negative. The basal metabolism tests were $+26,+11,+15$ and +7 per cent. Sugar tolerance test (100 grams of glucose):

\begin{tabular}{|c|c|}
\hline Time & $\begin{array}{c}\text { Blood sugar } \\
\text { mgm. per } 100 \text { cc. }\end{array}$ \\
\hline Fasting ... & $\ldots 97.6$ \\
\hline 30 minutes & $\ldots \ldots \ldots \ldots \ldots \ldots .114 .0$ \\
\hline 90 minutes & $\ldots \ldots \ldots \ldots \ldots \ldots \ldots 170.4$ \\
\hline 180 minutes & .. 138.0 \\
\hline 240 minutes & $\ldots \ldots \ldots \ldots \ldots \ldots \ldots 112.0$ \\
\hline
\end{tabular}

Roentgenograms showed a thickened skull, an enlarged sella turcica, enlargement of the sinuses, prominent man- 
dible with separation of the teeth and tufting of the terminal phalanges of the hands and feet.

Metabolic studies were made at the time of the first admission. The patient was then discharged home for 10 days on the same low calcium diet. During this 10day period and the subsequent metabolic study period, he received 10 minims of Lugol's solution each day. The basal metabolic rates during this period varied from +1 to +13 . The third metabolic study was made 40 days after the last of two courses of deep x-ray therapy. During each course of treatment he received a total of $960 \mathrm{r}$ to each of the temporal and frontal regions. The eight basal metabolism tests during the third metabolic period varied from +5 to +24 . The patient's condition was seemingly unchanged as a result of the treatment given.

Impression: Acromegaly with slight to moderate hyperpituitarism probably due to an acidophilic adenoma of the anterior lobe of the pituitary.

Case IV, Mrs. M. D., a 34-year-old, married, Greek housewife, entered the hospital January 17, 1928, complaining of amenorrhea. Her appendix had been removed 15 years before. Otherwise her past history was essentially negative. The patient's family was of large stature and she was considered a large woman prior to the onset of her present illness. Hypertrichosis, a family characteristic, had been present for 15 years. Three months after her marriage, 8 years before admission, she had first noted swelling of the hands and fingers. She had had 6 miscarriages the first 2 years of married life. She had never become pregnant after " radium treatment of the womb" in 1922. Following the radium treatment amenorrhea gradually increased so that she menstruated only twice a year, and at such times her menstrual flow was very scanty. During the previous 3 years, the hypertrichosis of her face had increased, her facial appearance had changed, her hands and feet had definitely enlarged, and she frequently suffered from bitemporal headaches which were often accompanied by nausea, vomiting, diplopia and blurred vision. She had frequent epistaxis which she considered as evidence of vicarious menstruation, yet no relation to her regular menstrual periods could be established. She also compained of great fatigability, weakness, hyperhydrosis, intermittent pains in the extremities, loss of libido, occasional precordial pain and a tendency to constipation. A photograph taken in 1925 showed definite acromegalic features, whereas one taken 5 years before did not. She had gained 50 pounds in the previous 7 years.

Physical examination revealed a large-framed woman of good muscular development who showed obvious acromegalic features such as coarse, moist skin, hypertrichosis of the face, arms and legs, prominent superciliary ridges, a widened nose with large nares, thick lips, separated teeth, a prognathic lower jaw, large, thick hands and feet, broad fingers and toes. Examination of the heart was negative except for a systolic murmur heard over the entire precordium but loudest at the apex. The blood pressure was 118/76. Examination of the eyes showed indistinct disc margins and bitemporal upper quadrantic anopsia.

The laboratory examinations were as follows: Routine blood and urine examinations were considered normal. Blood and spinal fluid Wassermann tests were negative. The basal metabolism test was +17 per cent. Sugar tolerance test (100 grams of glucose) :

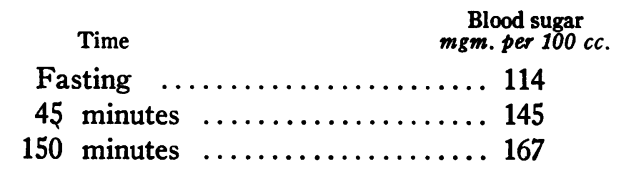

Roentgenograms disclosed an unusually thick skull, particularly of the frontal bones, very large sinuses, marked hypertrophy of the mandible, a definitely enlarged sella turcica, with thinning and irregularity of the posterior clinoid processes. X-ray examination of the gastrointestinal tract showed a large, dilated, atonic stomach with sluggish peristalsis; the rectum, sigmoid and ascending colon were very much dilated with absent haustral markings; the cecum was large but showed normal haustrations. The patient was studied before a course of deep $\mathrm{x}$-ray therapy was given. Following this treatment, the patient's headaches were less frequent and her weakness seemed less marked.

Impression: Acromegaly with slight hyperpituitarism probably caused by an acidophilic adenoma of the anterior lobe of the pituitary gland.

Case V, Mrs. R. M., a 46-year-old, white, widowed, housekeeper, entered the hospital October 19, 1928, complaining of headaches. Her past history was not significant. There was no family history of gigantism. She had 2 children living and well; there had been no other pregnancies and no miscarriages. Six years before she was told that her facial appearance had changed. Two years later enlargement of the hands and feet was sufficiently marked to require larger gloves and shoes. The changes noted in her facial features, hands and feet gradually increased up to 6 months prior to entry. Amenorrhea had been present for 31/2 years. In 1924 she first noticed enlargement of the thyroid. She was seen in the thyroid clinic that year. Her symptoms were hot flashes, nervousness, diarrhea, palpitation, hyperhydrosis and occasional frontal headaches. Examination at that time showed typical acromegalic features but no signs suggesting exophthalmic goiter, although her basal metabolism was +30 per cent. The sella turcica appeared normal on $x$-ray examination. Her vision and visual fields were normal. Three weeks before admittance to the hospital, she developed a severe occipitofrontal headache associated with nasuea, vomiting, diplopia and dimness of vision. This attack lasted 2 days. She had 4 other such attacks, each being less severe and of shorter duration.

Physical examination revealed a medium sized woman, fairly well developed and nourished. The following acromegalic features were present: prominent superciliary 
ridges, a broad nose, a dry, thick skin, moderately thick lips, an enlarged tongue, moderate prognathism, with moderate separation of the teeth, enlarged, spade-like hands and enlarged feet. The eyes were slightly prominent. There was paralysis of the left external rectus muscle. Examination of the fundi showed slight haziness of the upper right disc margin. The tonsils were enlarged and appeared cryptic. The thyroid was definitely enlarged; no nodules were felt and no thrill or bruit was present. The heart was normal except for a systolic murmur at the apex. The blood pressure was $120 / 80$. The lungs were negative. The abdominal examination was negative. Neurological examination was normal.

The laboratory examinations were as follows: All urine examinations showed a trace of albumin; no other abnormalities were found. Red blood cell count 4,200,000; white blood cell count 8,100 ; hemoglobin 70 per cent. The blood smear showed 53 per cent polymorphonuclears, 39 per cent small lymphocytes, 7 per cent large mononuclears, and 1 per cent eosinophils. Blood Wassermann was negative. The basal metabolism test was -24 per cent. Roentgenogram of the sella turcica showed definite enlargement when compared with that taken in 1924. There was slight tufting of the terminal phalanges.

Impression : Acromegaly probably due to a slow-growing acidophilic adenoma of the anterior lobe of the pituitary. Hyperpituitarism had probably existed at some previous time but the clinical studies at the time the patient was studied suggested decreased pituitary activity.

\section{BIBLIOGRAPHY}

1. Zwarenstein, $H$., The endocrine glands and calcium metabolism. Biol. Rev., 1934, 9, 299.

2. Houssay, B. A., Certain relations between the parathyroids, the hypophysis and the pancreas. New England J. Med., 1936, 214, 1128.

3. Hertz, S., and Kranes, A., Parathyreotropic action of the anterior pituitary: histologic evidence in the rabbit. Endocrinology, 1934, 18, 350.

4. Anselmino, K. J., Hoffmann, F., and Herold, L., Über die parathyreotrope Wirkung von Hypophysenvorderlappenextrakten. Klin. Wchnschr., 1933, 12, 1944. Ibid., 1934, 13, 45.

5. Marenzi, A. D., and Gerschman, R., Substancias minerales del plasma de los perros hipofisoprivos. Rev. Soc. argent. de biol., 1934, 10, 131.

6. Hogben, L., Charles, E., and Slome, D., Studies on the pituitary. VIII. The relation of the pituitary gland to calcium metabolism and ovarian function in xenopus. J. Exper. Biol., 1931, 8, 345. IX. Changes in blood calcium following injection of anterior lobe extracts and sexual excitement in female rabbits. Ibid., 1932, 9, 139.

7. Shapiro, H. A., and Zwarenstein, H., Metabolic changes associated with endocrine activity and the reproductive cycle in xenopus laevis. I. Effects of gonadectomy and hypophysectomy on the calcium content of the serum. J. Exper. Biol., 1933, 10, 186.

8. Gerschman, R., and Marenzi, A. D., Acción del extracto alcalino de lobulo anterior de hipofisis sobre las substancias minerales del plasma. Rev. Soc. argent. de biol., 1935, 11, 500.

9. Thompson, K. W., and Cushing, H., Experimental pituitary basophilism. Proc. Roy. Soc., London, s. B, 1934, 115, 88 .

10. Marenzi, A. D., and Gerschman, R., Hipofisis y sub= stancias minerales de la sangre. Rev. Soc. argent. de biol. (supp.), 1934, 10, 350.

11. Friedgood, H. B., The effect of an alkaline extract of the anterior hypophysis upon the weight of the spleen and adrenal glands and upon the blood calcium level. Endocrinology, 1936, 20, 159.

12. Friedgood, H. B., and McLean, R., Studies of calcium and phosphorus metabolism. XXV. The effect of an hypophyseal extract upon the serum calcium and phosphorus. Am. J. Physiol., 1937, 118, 588.

13. Pugsley, L. I., and Anderson, E. M., The effect of the growth and thyreotropic hormones of the anterior pituitary upon the calcium metabolism of the rat. Am. J. Physiol., 1934, 109, 85.

14. Cushing, H., and Davidoff, L. M., The pathological findings in four autopsied cases of acromegaly with a discussion of their significance. Monographs of the Rockefeller Institute for Medical Research, No. 22, April, 1927.

15. Scriver, W. de M., and Bryan, A. H., Observations upon the calcium and phosphorus metabolism in a case of acromegaly showing marked osteoporosis. J. Clin. Invest., 1935, 14, 212.

16. Langeron, L., and others, Acromégalie, diabète calcique puis diabète sucré, traitement radiotherapique. Rev. franç. d'Endocrinol., 1933, 11, 177.

17. Bauer, W., and Aub, J. C., Studies of inorganic salt metabolism. I. The ward routine and methods. J. Am. Dietetic Assn., 1927, 3, 106.

18. Friedgood, H. B., The iodine remission in experimental "exophthalmic goiter" of guinea pigs. J. Pharmacol. and Exper. Therap., 1935, 53, 46.

19. Tibbetts, D. M., and Aub, J. C., Magnesium metabolism in health and disease. III. In exophthalmic goiter, basophilic adenoma, Addison's disease, and steatorrhea. J. Clin. Invest., 1937, 16, 511.

20. Aub, J. C., and Tibbetts, D. M., Do the pituitary and adrenal glands influence calcium or magnesium metabolism? (Summary) Trans. Assn. Am. Physicians, 1936, 51, 129.

21. Aub, J. C., and others, Studies of calcium and phosphorus metabolism. III. The effects of the thyroid hormone and thyroid disease. J. Clin. Invest., 1929, 7, 97.

22. Freyberg, R. H., and Grant, R. L., Calcium and phosphorus metabolism in a verified case of pituitary basophilism. Arch. Int. Med., 1936, 58, 213. 